University for Business and Technology in Kosovo

UBT Knowledge Center

Nov 8th, 12:00 PM - 12:15 PM

\title{
Integration of the Kosovo Road Network into the Pan-European Transport Network
}

\author{
Ramadan Mazrekaj \\ Albanian Consultants Association, rmazrekaj@hotmail.com \\ Betim Reqica \\ Ministry of Infrastructure, breqica@gmail.com
}

Follow this and additional works at: https://knowledgecenter.ubt-uni.net/conference

Part of the Architecture Commons

\section{Recommended Citation}

Mazrekaj, Ramadan and Reqica, Betim, "Integration of the Kosovo Road Network into the Pan-European Transport Network" (2014). UBT International Conference. 17.

https://knowledgecenter.ubt-uni.net/conference/2014/all-events/17

This Event is brought to you for free and open access by the Publication and Journals at UBT Knowledge Center. It has been accepted for inclusion in UBT International Conference by an authorized administrator of UBT Knowledge Center. For more information, please contact knowledge.center@ubt-uni.net. 


\title{
Integration of the Kosovo Road Network into the Pan-European Transport Network
}

\author{
Ramadan Mazrekaj ${ }^{1}$, Betim Reqica ${ }^{2}$ \\ ${ }^{1}$ Albanian Consultants Association, \\ ${ }^{2}$ Ministry of Infrastructure, \\ $\underline{\text { rmazrekaj@ hotmail.com }}$, breqica@gmail.com $^{2}$
}

\begin{abstract}
Integration of the Kosovo road network in the Pan-European network, means, first of all, to establish a road system and infrastructure that is in accordance with the requirements and standards of Pan-European road networks, and secondly, to use / promote the geographical position of the Kosovo main road network, making it able to meet the requirements of Pan-European road networks. Beside the fulfillment of the constructive/ technical / geometrical requirements towards the road infrastructure, the road transport network needs to guarantee to its users a high, uniform and continuous level of services, as well as road commodity and safety. In this thesis, there is also treated the position of the Kosovo road network, the main road directions of Kosovo and its compatibility with the needs of the Pan-European connection, the roads and corridors of the Balkans in context to the Pan-European corridors. In the continuation of the thesis, through the Software Trans CAD, there is conducted the analysis and the modeling of the Kosovo and Balkan road network, the analysis of the best connection and the shortest roads of Balkan countries. The identification of obstruction and the presentation of possibilities for the orientation of the flux of goods in a shorter road, in the function of reduced transport costs. The comparison of advantages and disadvantages of the existing roads (the eighth Pan-European corridor, the Tenth Pan-European Corridor, Via Egnatia etc), the economical sustainability and competition, the service quality, limitations (both natural, environmental / season or humane), transport capacities
\end{abstract}

Keywords: Kosovo, Roads, modeling with Trans CAD.

\section{Introduction}

The development of road infrastructure is the determining factor of economic development of our country, it is an essential element of economic cooperation, scientific, cultural, free movement of people etc., cooperation which is wider and deeper every day, being the current priority. It is clear that the Balkan and European integration, the first phase of which is the Stability Pact, constrain the integration of road network of our country in the Pan-European infrastructural network transport, as an appropriate link with the Trans-European network of European community. Final stabilization of peace in the Balkans, coexistence in diversity, free movement of goods, capital and ideas requires you to shorten to the maximum the time of contact between producers and users. And it is Kosovo that has something to offer in this field to the Balkans and beyond, with its important position as a connecting bridge, and important link of the Pan-European corridors. Kosovo is located in the center of Eastern Europe and it is claimed to have been historically an important crossroad of the Balkan Peninsula. Road construction VI and VII, their connection with the Pan European corridors VIII and X, enabling integration and better links of Kosovo with neighboring countries but also in neighboring countries with each other, this connection enables that a part of the international traffic (goods and Passengers) from Eastern Europe can be redirected towards Kosovo to the Adriatic sea ports, and from the Adriatic to the Black Sea through Kosovo as the shortest route. 
Table 1. The road network in Kosovo

\begin{tabular}{lcclll}
\hline $\begin{array}{l}\text { Competence } \\
\text { / Type }\end{array}$ & Paved & $\%$ & Unpaved & $\%$ & $\begin{array}{l}\text { Total in } \\
\mathrm{Km}\end{array}$ \\
\hline MI & 1810 & 94.2 & 111 & 5.8 & 1921 \\
Motorway & 68 & & & & 68 \\
National & 599 & 99.3 & 4 & 0.7 & 603 \\
Regional & 1173 & 91.6 & 107 & 8.3 & 1280 \\
Municipal & & & & & 5034 \\
Local & & & & & 4463 \\
Urban & & & & 571 \\
Total & & & & 6985 \\
\hline
\end{tabular}

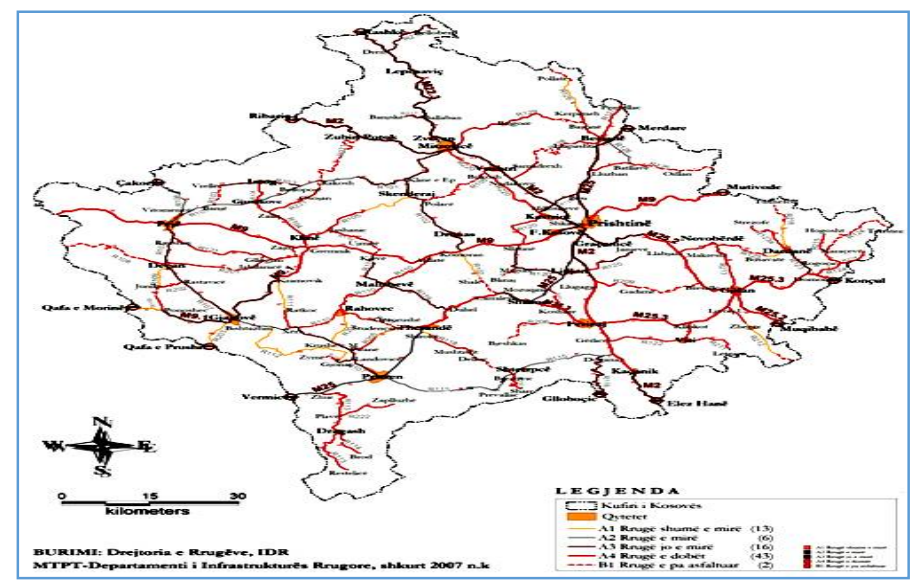

Fig. 1. Map of national and regional roads in Kosovo

The primary road network in Kosovo

In Figure 2, below, there is presented the primary (main) road network of Kosovo which enables connection to the Core Road Network of South East Europe (SEETO) and further complete of integration in Pan - European Transport networks.

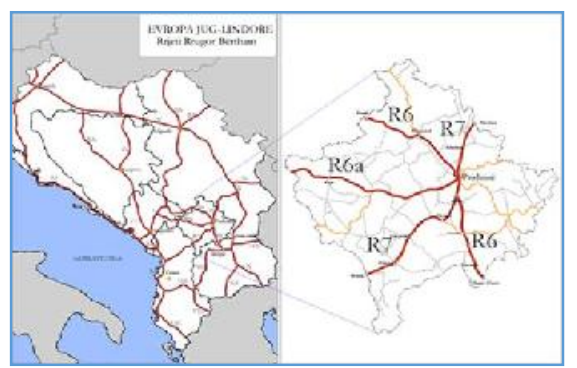

Fig. 2. Kosovo's primary road network that integrates with Network SEETO and further the Pan European networks 
The road network of the first category includes the new highway (until now built $82 \mathrm{~km} \mathrm{long}$ ) that connects Kosovo from border in Vermica (border with Albania) with Kosovo's capital Prishtina, to continue further to the border with Serbia in Merdare border crossing point, further being connected with the city of Nis which is a transit joint of the Pan European Corridor X.

\section{Pan-European Transport Corridors (PETC)}

Ten Pan-European Transport Corridors are determined in the second Pan-European Transport in Crete, March 1994, as routes in Central and Eastern Europe that require major investments over the oncoming ten to fifteen years. Other additions were made at the third conference in Helsinki in 1997, therefore, these corridors are named as "Crete Corridors" or "Helsinki Corridors", regardless of their geographical location. A tenth corridor was proposed after the end of the war between the states of the former Yugoslavia. Recently, there is approved an eleventh corridor stretching from Romania, through Serbia and Montenegro to Italy. It is known that this corridor will pass through Belgrade and will incorporate highway Belgrade - Bar (Montenegro). Corridors, in varying order, include road, rail and navigable waterway itineraries.

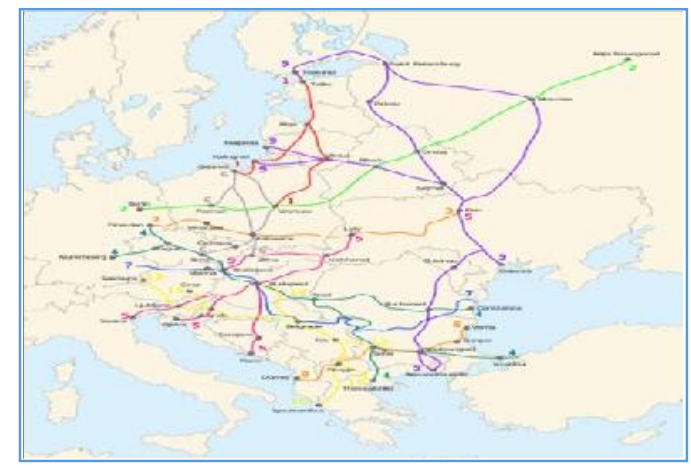

Fig. 3. Pan European Network Corridor

Table 2. Ten Pan European Corridors

\begin{tabular}{ll}
\hline I & (North-South) Helsinki - Tallinn - Riga - Kaunas and Klaipeda \\
& - Warsaw and Gdansk \\
& Branch A (Via/Rail Hanseatica) - St. Petersburg - Riga - \\
& Kaliningrad - Gdansk - Lübeck \\
& Branch B (Via Baltic/E 67) - Helsinki - Warsaw. \\
\hline II & (East-West) Berlin - Poznań - Warsaw - Brest - Minsk - Smolensk \\
& - Moscow - Nizhny Novgorod \\
III & Brussels - Aachen - Cologne - Dresden - Wrocław - Katowice - \\
& Kraków - Lviv - Kiev \\
& Branch A - Berlin - Wrocław \\
IV Dresden/Nuremberg - Prague - Vienna - Bratislava - Győr - \\
Budapest - Arad - Bucharest - Constanţa /Craiova - Sofia - \\
Thessaloniki / Plovdiv - Istanbul.
\end{tabular}




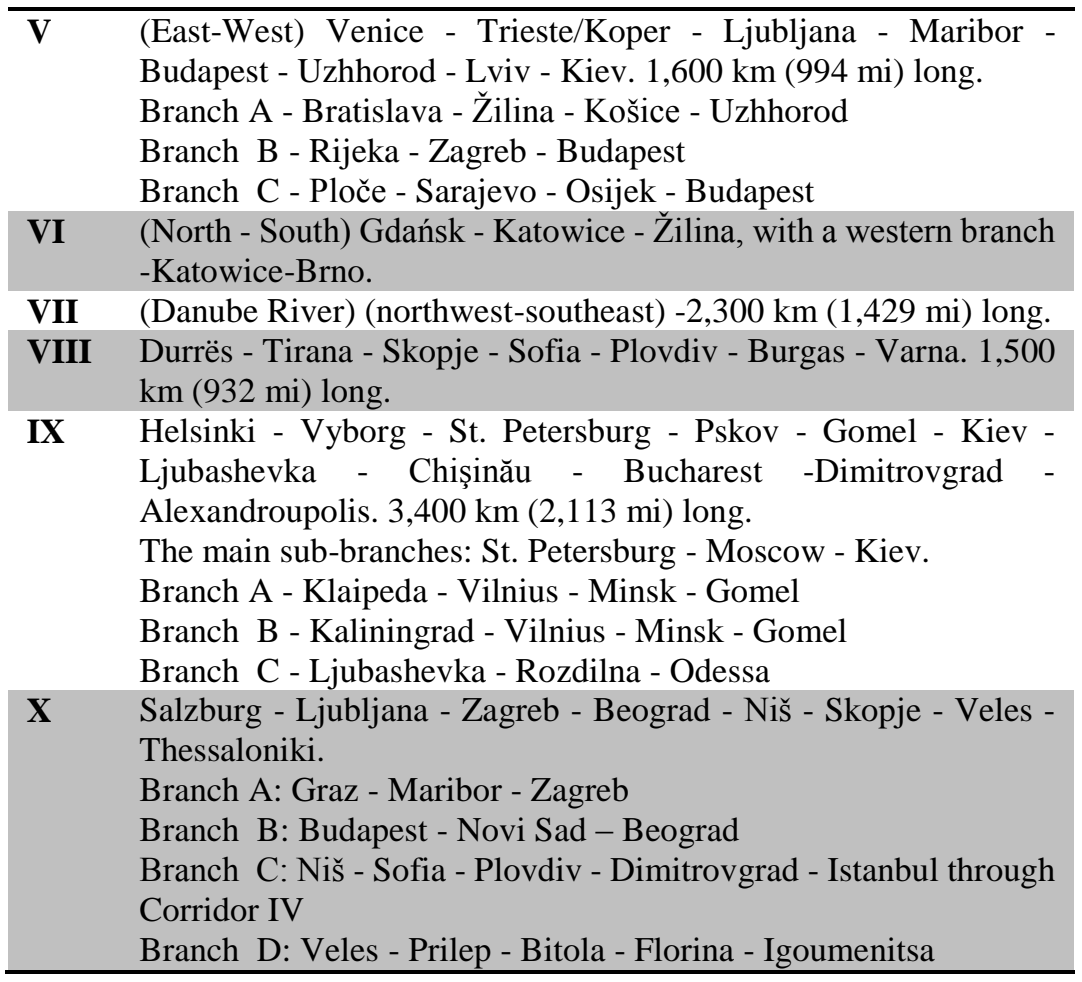

In addition to the above corridors, later determined four transportation areas as important modal corridors:

Barents Euro-Artic Transport Zone: Multimodal Transportation Zone covering the northern provinces of Sweden, Finland and Norway as well as Murmansk and Arkhangelsk and Karelia Republics and Komi of the Russian Federation.

Black Sea Transport Area: Seaside countries of the Black Sea (Turkey, Georgia, Russia, Ukraine, Romania, Bulgaria) as well as Greece and Moldova (observer status to Armenia and Azerbaijan)

Adriatic Ionian Sea Transport Area Sea: Adriatic and Ionian Seaside countries (Albania, Bosnia and Herzegovina, Croatia, Greece, Italy, Slovenia, Serbia and Montenegro)

Mediterranean Transport Area (MEDA countries): Algeria, Cyprus, Egypt, Israel, Jordan, Lebanon, Malta, Morocco, Palestinian Territories, Syria, Tunisia and Turkey.

\subsection{Pan European Road Network who influence in Kosovo Road Network}

Corridors and branches which directly affect transport and Kosovo road network are:

Corridor IV - Dresden / Nuremberg - Prague - Vienna - Bratislava - Györ - Budapest - Arad - Bucharest - Constanţa / Craiova - Sofia - Thessaloniki / Plovdiv - Istanbul: creating links through Serbia and Macedonia.

Corridor V - (East-West) Venice - Trieste / Koper - Ljubljana - Maribor - Budapest - Uzhhorod - Lviv - Kyiv: creating links with Sarajevo (BH) via Serbia and Montenegro.

Corridor VII - (Danube River) (northwest-southeast): as waterways who performs multi-modal transport corridors IV, V, VIII and X.

Corridor VIII - Durres - Tirana - Skopje - Sofia - Plovdiv - Burgas - Varna: about creating routes that pass through the territory of Albania and Macedonia.

Corridor X - Salzburg - Ljubljana - Zagreb - Belgrade - Niš - Skopje - Veles - Thessaloniki: creating connection via Nis (SR) and Skopje (MK). 
Adriatic and Ionian Sea Transport Area: Adriatic and Ionian Seaside countries (Albania, Bosnia and Herzegovina, Croatia, Greece, Italy, Slovenia, Serbia and Montenegro).

Mathematical apparatus that will be used for implementation of the Project for the Integration of Kosovo road network into the PAN European network.

\subsection{Mathematical modeling of the road network and traffic.}

Classic model used in TransCAD for analysis, optimization and forecasting of traffic in a road network model with 4 Stages is held pursuant to the Protocol and the following steps: Trips generation: determines the frequency of origins or destinations in each zone by purpose of travel, based on the Land Use and demographics of families, as well as other socio-economic factors. Trips distribution: match origins with destinations, often through using function of gravity model, which is equivalent to an entropy maximization model. Modal choice calculates the trips between each origin and destination that uses a one way (mode) specified transportation. This is in the final logit model.

Shortest trips: sets the travels performed with specific ways of transportation between origin and destination, according to certain routes. For scheduling road itineraries there is applied the Wardrop principle for user equilibrium in which each user chose the shortest path (travel time), this choice is performed in the same way by any other user. Generation stage of trips (trips generation): mathematical models that are commonly used type of linear regression models as well as those using the gravitational at the distribution stage. Linear regression is used to find the correlation relationship between the number of movements from one area to generate the statistical data stochastic special qualities of the area, as are the number of residents, number of vehicles, macroeconomic indicators, etc. Cubic polynomial regression fits with a set of simulation dates. Band of reliability is a simultaneous generation with simultaneous 95\% confidence band constructed using the Scheffe method. The purpose of regression analysis is to model the expected value of a variable $y$ in terms of the value of an independent variable (or independent variables vector) $x$. In the simple linear regression, the model is of the following type:

$$
\mathrm{y}=\boldsymbol{a}_{0}+\boldsymbol{a}_{1} \mathbf{x}++\varepsilon
$$

In many configurations of such a linear relationship there may not stand, for example, in the case of traffic volume dependence of the degree of motorization (number of auto vehicles per thousand inhabitants). In this case we can propose a quadratic model in the form of:

$$
\mathrm{y}=\boldsymbol{a}_{0}+\boldsymbol{a}_{1} \mathbf{x}+\boldsymbol{a}_{2} \mathbf{x}^{2}+\varepsilon
$$

In this model, when the rate of motorization varies from $\mathrm{x}$ to $\mathrm{x}+1$ units, traffic volume varies with the derivative of the expression $a 1+2 a 2 x$. The fact that the change in volume of traffic depends on $x$ is what makes this non-linear dependence (This should not be confused with the statement that this is a non-linear regression, but this is still the case of a linear regression).

In general, we can model the expected value of $\mathrm{y}$ as a sequence of $\mathrm{n}$ polynomial benefiting the general model of polynomial regression:

$$
y=a_{0}+a_{1} x+a_{2} x^{2}+a_{3} x^{3}+\ldots+a_{n} x^{n}+\varepsilon
$$

The model of trip distribution: travel distribution model (O-D matrix) will use the Gravitational Model developed according to the following mathematical formula: 


$$
\mathrm{Tij}=\mathrm{k} *\left(\mathrm{Gia}^{*} \mathrm{Aja}\right) / \mathrm{Cijb}
$$

Where:

i \& j Zone of origins and destinations

Tij Passenger traffic flow (road transport) between zones $\mathrm{i}$ and $\mathrm{j}$

Gi Number of trips generated by the area of $i$

Aj Number of trips attracted by zone $j$

Cij Obstacles or resistance to travel between zones $\mathrm{i}$ and $\mathrm{j}$

(a function of travel time between $\mathrm{i}$ and $\mathrm{j}$ ),

Whereas the factors $\mathrm{a}, \mathrm{b}$ and $\mathrm{k}$ are constants to be determined conclusively as a value during the calibration of the model and represent the specific characteristics of concrete road infrastructure,

Modal choice stage: mathematical model used in this step is modeling logit model: logit is a number $\mathrm{p}$ between 0 and 1 that is calculated by the formula:

$$
\operatorname{logit}(p)=\log \left(\frac{p}{1-p}\right)=\log (p)-\log (1-p)
$$

The grounds of the logarithmic function has little importance in this case, as long as it is greater than 1 , but the natural logarithm with the base "e" is the one used most often.

Description of the shortest Trips: a mathematical model used in this case is the Wardrope or that of equilibrium users:

Determination of equilibrium: to determine the traffic routes and its derivatives of the transport network we must have regulations and they are known as Equilibrium Conditions of Wardrope (1952). Optimal equilibrium of the user can be found by solving non-linear programming problem:

$$
\min \sum_{a} \int_{0}^{v a} S a(x) d x
$$

2.2. Presentation of the GIS Map, Integration of Kosovo road network in to Pan European network created in TransCAD

The first step of the TransCAD application procedure is the definition of the service area of study. Given the topic of study: Integration of Kosovo's road network into the Pan-European networks of transport, we selected the study area as an area that lies between the area of the Pan-European Networks and TEN$\mathrm{T}$ (Trans-European Networks) and SEETO (South East European Transport Observatory ) zone.

This selection is based on the argument that the analysis of OD (origin-destinations) of the traffic of goods and passengers should not only include the SEETO project area, but also other important areas of the world that are traffic generators and/or centroid-joints influential in the network: Chisinau (Moldova), Lviv (Ukraine), Kiev (Ukraine), Odessa (Ukraine), Istanbul (Turkey), which are also important joints of the Pan-European Corridors. Also, they should be excluded from the system the 
centroid joints that are away from the field of impact on Kosovo's road network. In Figure 3 below presented our project study area, extracted from the Google satellite imaging system.

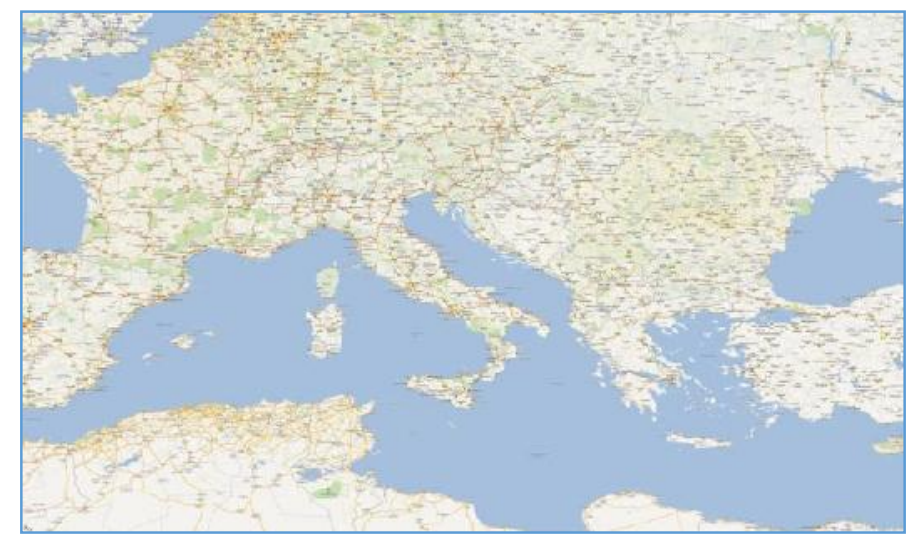

Fig. 4. Project Study Area, road network integration of Kosovo in Pan European network

Second step is to digitalize the study area, the road and rail network, for the zone of the Pan-European networks, SEETO, TEN-T and in more details for Kosovo and Albania. Digitalization was performed on geo-referenced images according to the coordinate system of Europe, on the program AutoCad Map 3D 2009.

The digitalization process was followed by the process of topology and the clean-up, preparing the system for the zonal polygonation as well as for establishing road and railroad networking as well as the introduction of the centroids in the system.

The further elaboration of the GIS File-system was performed in ArcGIS 9.3.2, where there was conducted the File-format conversion into "shape", which allows the transfer / conversion in the TransCAD program. The coordinates system used is: Class - Europe, Zone - Bartholomew. In Figure 4 below there is given the map of the study area - states, performed with TransCAD.

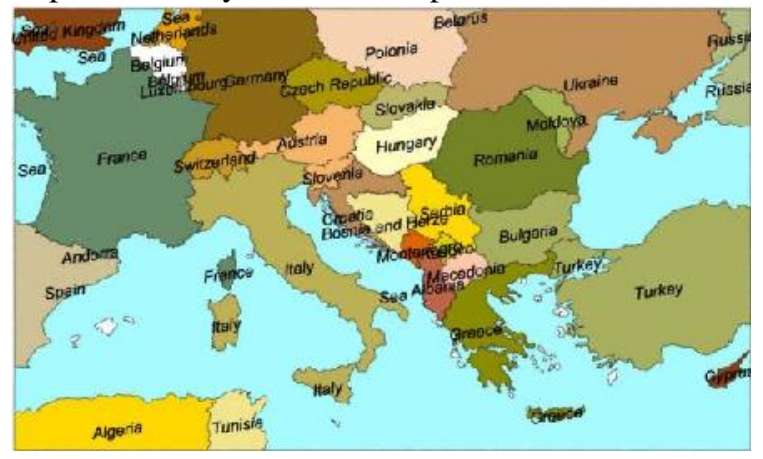

Fig. 5. Map of project study area road network integration of Kosovo in Pan European network

In the following, there are given the areas and transport networks of Kosovo and our Study Area. For each layer there is given the relevant panel with vector system of crosses and joints according to the road and rail network. Tables / Matrixes of the System: After creating the graph architecture and networking system of road and rail transport of Kosovo, the Pan-European Transport Network, TransEuropean Transport Network and Transport Networks of South East European Transport Observatory (SEETO), there is passed the information link for states, cities and centroid / important joints of the transport network, roads, railways and important geographical, technical, economic, demographic and social data, with geographical network / physical environment constructed in GIS to TransCAD's . 
The data inputs of the program are structured by a matrix of type date formats and Excel table format: xls, xlsx, which serve as the basis for converting formats transferable to TransCAD: dbd, bin, mtx, dbf and tab. The data were obtained from the European Counsel (EC) Reports on Pan-European Networks, Trans-European Networks of Transport (TEN-T), the European Road Transport Networks (TERN), project reports for South East European Transport Observatory (SEETO), from the World Bank publications, government projects and publications that contain important data on Kosovo. In the following image there is given the panel during the process of linking the data in the table with layers of transport networks and other system features.

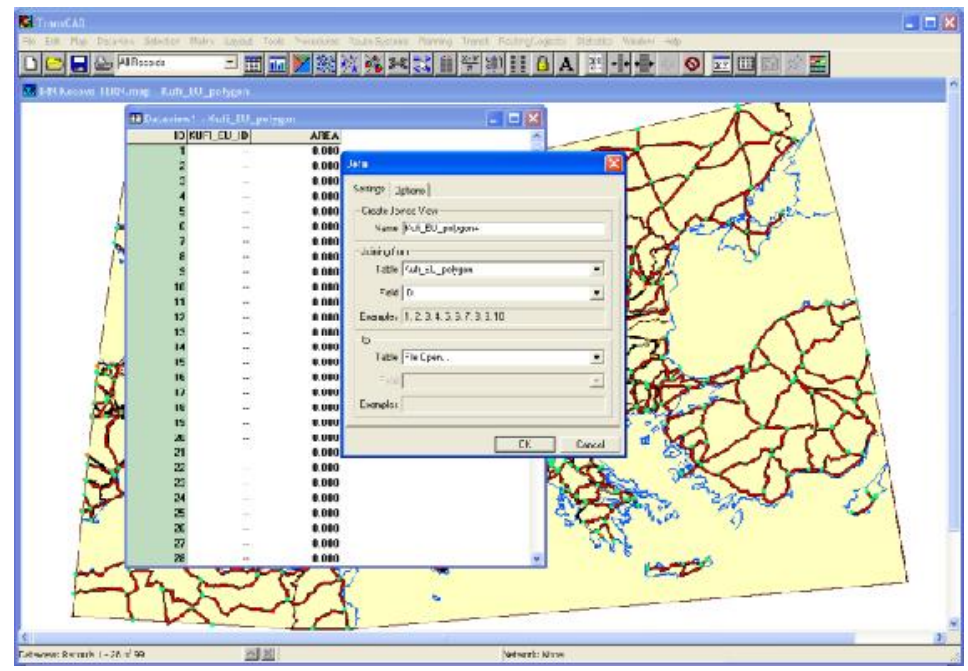

Fig. 6. Linking tables with layers of transport networks

Sourse: by author

On the basis of algorithms and procedures described, there was conducted comprehensive modeling of the primary and secondary road networks of Kosovo, primary Balkan road network (SEETO) and European road Network.

The model has the following features:

The model built for the road network also includes the main European rail network which is part of the European multimodal network and cannot be left out of the modeling process

Modeling of the study area includes 38 countries of which 36 European and two Mediterranean countries, with a total population of approximately 787.4 million and 24.7 million $\mathrm{km} 2$ area.

Graph of the study area consists of 102 sub areas, 38 primary centroids of capital cities and 102 secondary sub areas or major traffic centers, from 1,057 joints and 1,414 road arches as well as 321 joints and 414 railway arches. Transportation graphite model in the study area covers a road network with a total length of 5,668,712 km and a railway network in a length of $419.287 \mathrm{~km}$.

The model with the above mentioned characteristics is able to successfully accomplish the objectives of the study by determining: The existing transport capacity of Kosovo road network, for goods and passengers. Problems and Bottlenecks to the road network as well as interventions to be performed on the network to meet the standards of primary European road networks. Possible transport capacity of the Kosovo road network integrated in European networks as a direct result of meeting the standards.

Optimized and redistributed traffic in Kosovo and European networks, highlighting the volume of freight and passenger traffic that can pass on Kosovo's road network as a result of minimal itineraries and transportation costs that the network can offer. For the current project phase, we apply the model built only to the main road network in Kosovo to determine traffic flows on the network and reports the volume of road capacity to identify road sections where there are problems and traffic jams and 
interventions are needed to increase road capacity through its expansion, adding new lanes or passing on the highway.

\section{Determination of transit and international transport in Kosovo road network}

The essence of determining and integration process of Kosovo road network into Pan European networks is without a doubt the definition of international and transit traffic will be able to withdraw and afford Kosovo's main road network: Road 6, 6a, R $6 \mathrm{~b}$ and $\operatorname{Road} 7$. To solve this problem through modeling and simulation of Kosovo's road network (KRN) and the European Road Transport Network (TERN), it is necessary to calculate the matrix of Origin Destination (OD) of the movement of goods and passengers between states belonging to the Transport network, Kosovo road Network and Trans European Transport Networks.

Table 3. Reports the value (Euro) / Weight (tons) in international trade

\begin{tabular}{llll}
\hline \multirow{2}{*}{ Member states } & \multicolumn{2}{c}{ Value ratio $€$ / Ton goods } & \\
\cline { 2 - 4 } Croatia & \multicolumn{1}{c}{ Import } & Export & Import + Export \\
Iceland & 799.31 & $1,696.56$ & $1,240.93$ \\
Norway & $1,945.83$ & $1,633.09$ & $1,805.67$ \\
Switzerland & 562.64 & $2,193.06$ & 746.23 \\
Albania & $7,328.13$ & $3,216.54$ & $4,268.90$ \\
Kosovo & 833.91 & $1,009.62$ & 946.24 \\
Belarus & $2,394.37$ & $1,436.21$ & $1,533.66$ \\
Bos. and H & 423.66 & $2,589.75$ & 899.02 \\
Montenegro & 737.22 & $1,320.70$ & $1,001.70$ \\
Macedonia & $1,395.00$ & $1,573.98$ & $1,558.58$ \\
Moldova & $1,955.51$ & $1,338.81$ & $1,522.27$ \\
Serbia & $1,348.38$ & $1,826.86$ & $1,519.54$ \\
Russia & $1,237.24$ & $1,903.09$ & $1,607.94$ \\
Turkey & 547.97 & $4,205.88$ & 803.74 \\
Ukraine & $2,155.80$ & $1,659.21$ & $1,822.61$ \\
\hline
\end{tabular}

Table 4. Modal Split of international transport in Kosovo, based on the Euro value

\begin{tabular}{lllll}
\hline & \multicolumn{2}{c}{$\mathbf{2 0 1 2}$} & \multicolumn{1}{c}{$\mathbf{2 0 1 3}$} & \\
\cline { 2 - 5 } Sea transport & \multicolumn{1}{c}{ Value } & $\%$ & \multicolumn{1}{c}{ Value } & $\%$ \\
Rail transport & 3,992 & 0 & 13,647 & - \\
Road transport & $1,444,292$ & 0.9 & $3,432,206$ & 1.20 \\
Air Transport & $154,137,095$ & 93.2 & $275,958,514$ & 93.90 \\
Pos.Delivery & $1,805,088$ & 1.1 & $1,157,930$ & 0.40 \\
Com.Transport & 937,906 & 0.6 & $3,075,529$ & 1.00 \\
Fix.Tra.Inst & 0 & 0 & 0 & - \\
Tran.Thro.Riv & $0,999,215$ & 4.2 & $10,123,743$ & 3.40 \\
Total exports & $165,327,587$ & 0 & 0 & - \\
Sea transport & 470,747 & 100 & $293,761,569$ & 100 \\
Rail transport & $106,459,444$ & 0 & 193,856 & - \\
\hline
\end{tabular}




\begin{tabular}{lllll}
\hline Road transport & $1,713,828,463$ & 88.6 & $1,870,498,209$ & 88.80 \\
\hline Air transport & $33,149,797$ & 1.7 & $34,610,784$ & 1.60 \\
\hline Pos.Delivery & $11,328,862$ & 0.6 & $7,547,190$ & 0.40 \\
\hline Com.Transport & $19,147,777$ & 1 & $29,213,361$ & 1.40 \\
\hline Fix.Tra.Inst & $51,098,473$ & 2.6 & $43,890,329$ & 2.10 \\
\hline Tran. Thro.Riv & 57,650 & 0 & 134,087 & - \\
\hline Total imports & $1,935,541,213$ & 100 & $2,105,459,829$ & 100 \\
Sea transport & 474,739 & 0.02 & 207,503 & 0.01 \\
Rail transport & $107,903,736$ & 5.14 & $122,804,220$ & 5.12 \\
\hline Road transport & $1,867,965,558$ & 88.91 & $2,146,456,723$ & 89.46 \\
Air transport & $34,954,885$ & 1.66 & $35,768,714$ & 1.49 \\
Pos.Delivery & $12,266,768$ & 0.58 & $10,622,719$ & 0.44 \\
\hline Comb.Tra & $19,147,777$ & 0.91 & $29,213,361$ & 1.22 \\
\hline Fix.Tra.Inst & $58,097,688$ & 2.77 & $54,014,072$ & 2.25 \\
\hline Tra.Thro.Riv & 57,650 & 0.00 & 134,087 & 0.01 \\
Impo. + expor. & $2,100,868,800$ & 100 & $2,399,221,398$ & 100. \\
\hline
\end{tabular}

Table 5. Modal Split of international transport in Kosovo, the base weight, in tons

\begin{tabular}{|c|c|c|c|c|}
\hline \multirow{2}{*}{$\begin{array}{l}\text { Value/weight } \\
\text { proportion }\end{array}$} & \multirow[t]{2}{*}{$€ /$ ton } & \multicolumn{2}{|c|}{ Import + Export } & \multirow{2}{*}{$\begin{array}{c}\text { Mod.Split } \\
\%\end{array}$} \\
\hline & & Euro & Ton & \\
\hline Sea & 1,011 & 207,503 & 205 & 0.02 \\
\hline Road & 2,692 & $2,146,456,723$ & 797,346 & 68.48 \\
\hline Rail & 472 & $122,804,220$ & 260,345 & 22.36 \\
\hline Air & 52,294 & $46,391,433$ & 887 & 0.08 \\
\hline Water & 400 & 134,087 & 335 & 0.03 \\
\hline Combined & 472 & $29,213,361$ & 61,893 & 5.32 \\
\hline Fix.Equip. & 1,011 & $43,890,329$ & 43,413 & 3.73 \\
\hline Total & & $2,389,097,656$ & $1,164,425$ & 100.00 \\
\hline
\end{tabular}

\subsection{Assessment of transport capacity of Kosovo road network}

For this project we apply the model built only for Kosovo main road network to establish traffic flows on the network and reports of the volume of road capacity, to identify the road sections where there have problems, traffic jams, and which interventions are needed to increase road capacity through its expansion, adding new lanes or crossing on the highway. Table 8 and 9 show the traffic data used to determine the capacity of roads, and reports volume / road capacity. Results of the TransCAD's application presented in the following table, relevant traffic flow of the Kosovo road network.

Table 6. AADT and Report Volume /capacity in Kosovo's main road network (Rout 6,6a,6b, and Rout 7)

\begin{tabular}{lllll}
\hline Roads & AADT & \multicolumn{3}{c}{ Volume / Capacity Proportion } \\
& & 2012 & 2018 & 2021 \\
\hline R-6 & 7,393 & 0.6 & 0.8 & 0.92 \\
R-7 & 10,445 & 0.86 & 1 & 1 \\
R-6 & 20,941 & 0.58 & 0.79 & 0.92 \\
R-7 & 6,487 & 0.52 & 0.7 & 0.81 \\
R- 6 & 12,031 & 0.97 & 1 & 1 \\
R-6b & 8,070 & 0.65 & 0.87 & 0.72 \\
R- 6b & 16,414 & & 0.62 & 1
\end{tabular}




\begin{tabular}{ll|l|l|l} 
R-7 & 10,795 & 0.87 & 1 & 1 \\
R-7 & 12,487 & & & 1 \\
R-7 & 8,554 & 0.69 & 0.92 & 1 \\
R- 6a & 10,812 & 0.87 & 1 & 1 \\
R- 6a & 20,855 & 0.59 & 0.79 & 1 \\
R- 6a & 8,144 & 0.66 & 0.88 & 0.92 \\
R-6a & 2,819 & & & 0.8 \\
R- 6b & 7,394 & 0.6 & 0.8 & \\
R-7 & 7,695 & & & \\
\hline
\end{tabular}

Sourse: by author

When volume/road proportion capacity amounts to 0.8 , according to European and American standards should be increased road capacities through expansion, increasing the number of lanes or passing on a highway because the level of service deteriorates significantly.

2. The maximum value of the ratio volume / road capacity is 1 , and it shows

that the route has the lowest level of service F, which signals its blocking.

Table 7 below given color codes and intervention required to increase transportation capacity, traffic volume, of road infrastructure.

Table 7. Color code and Level of service ( LOS )

\begin{tabular}{llr}
\hline $\begin{array}{l}\text { Color } \\
\text { code }\end{array}$ & $\begin{array}{l}\text { Level of Service } \\
\text { (LOS) }\end{array}$ & \multicolumn{1}{c}{$\begin{array}{c}\text { Intervention Requested } \\
\text { C \& D }\end{array}$} \\
\hline C \& D & $\begin{array}{l}\text { Increasing road capacity is not required. } \\
\text { The free flow } \\
\text { Plan to increase road capacity after } 5-7 \text { years } \\
\text { D \& E }\end{array}$ & $\begin{array}{l}\text { Plan to increase road capacity after 3-4 years } \\
\text { Make and increase road capacity }\end{array}$ \\
F & Urgently increases the capacity of the road \\
\hline
\end{tabular}

Sourse by:Author

\section{Conclusion}

There can be no sustainable development of transport in the Balkans without of its integration in transport networks in European networks and without integrating Kosovo road network into the European road network, for themselves Kosovo position in the center of the Balkan peninsula.

With consideration that Kosovo's transportation network meets the Trans European standards of Transport Networks (TEN-T), and the Trans European Road Network (TERN), and after determining the OD matrices of goods and passengers in the study area of Kosovo road network integration in Pan European network (RNI in PERN), with TransCAD's side was calculated the flow of vehicles in Kosovo's main road network (roads 6, 6a, 6b, and 7) defining clearly the Kosovo road network capacity for a period of time from $2012-2021$.

Integration of Kosovo's road network in Pan European Network creates the necessary conditions for withdrawal, in the primary road network in Kosovo, to an expected traffic of goods, international and transit through the territory of the Republic of Kosovo, about 10 mil/tons of goods per year, or about 
$1,270,359$ heavy trucks (HGV) a year, needed to transport them. Annual Average Daily Traffic (AADT) was 3,480 trucks/day or about 10,440 equivalent cars (PCU).

Based on these outputs of the TransCAD derives that the orientation of the expected traffic of goods and passengers will have transit or origin/destination the territory of Kosovo is a significant value that fully justify the significant investment for radical improvement road infrastructure, especially the construction of roads 6 and 7 that connect and integrate Kosovo into the Pan-European network, as well as road transport operation in Kosovo, applying European standards in this field.

\section{References}

1. Mazrekaj R: PhD thesis, study of Integration of Kosovo's road network in Pan

2. European Network Aimed at Sustainable Development of transport in the Balkan

3. region

4. SEETO "network Comprehensive Development Plan 2012 - Multiannual Plan

5. 2012-2016"

6. Multi-Modal Transport Strategy of Kosovo, since 2009.

Technical Assistance: Support in the Implementation of the Community

7. Transportation Agreement, Prishtina in 2012.

Willumsen LG (1998) Modelling Transport Studies. 1998 California

Transport Infrastructure Regional Study (TIRS) in the Balkans. Louis Berger

8. SA. 2001

Technical Assistance: Support in the Implementation of the Community

9. Transportation Agreement, Pristina in 2012.

Feasibility Study and Environmental Assessment for Two Main Road Axes in

10. Kosovo (Road VI and VII), 2007

The Detail Project Design for motorway on the route from the junction Lipljan up

11. to Eat Han (border with Macedonia), Economic Analysis report, 2009.

Trade Exchanges Kosovo, the Kosovo Statistics Agency.

Kosovo Customs

Road traffic flow of Vehicles in the streets of Kosovo, the Kosovo Ministry of

12. Infrastructure

HCM- 2000

13. http://www.iru.org/

14. http://www.oecd.org/cem/

15. http:// www.tinavienna.at/

16. http:// www.unece.org/trans/

17. http:// www.worldbank.org.ba/ 